\title{
$\mathrm{fcc}$ 格子反強磁性体 $\mathrm{NiS}_{2}$ における幾何学的スピンフラストレーション
}

松浦 直人

東京大学物性研究所

\section{Geometrical Spin Frustration in the fcc Antiferromagnet $\mathrm{NiS}_{2}$}

\section{Masato Matsuura \\ ISSP, The University of Tokyo

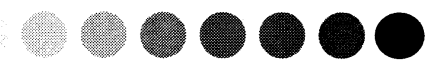

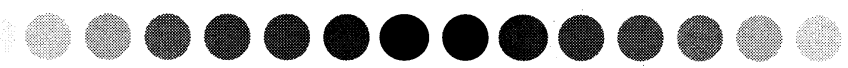

\begin{abstract}
Inelastic neutron scattering measurements have been performed to study geometrical spin frustration effects on the magnetism in the fcc antiferromagnet $\mathrm{NiS}_{2}$. A honeycomb pattern of magnetic diffuse scattering along the Brillouin zone boundary was observed up to much higher temperature than $T_{N}$ indicating a direct evidence for frustrated magnetism. Theoretical analyses revealed that the system is located very close to the phase boundary between the type-I antiferromagnetic $(\mathrm{AF})$ ordered phase $\left(\mathrm{Q}_{\mathrm{AF}}=(1,0,0)\right)$ and the type II AF ordered phase $\left(\mathrm{Q}_{\mathrm{AF}}=(1 / 2,1 / 2,1 / 2)\right)$. AF long-range order lifts the degeneracy and gives rise to a spectral shift from a low energy to a finite energy $\sim \mathrm{J}$.

Keywords: geometrical spin frustration; fcc antiferromagnet; Mott Insulator; Neutron Scattering,
\end{abstract}

\section{1.はじめに}

近年，構造上の理由から大きな磁気摇らぎを持 つ(幾何学的スピンフラストレーション) 系の新 しい物性現象が注目を浴びている。そのような系 は共通して反強磁性相関を持つ三角格子を含み

(Fig.1)，スピンを反対向きに揃えようとすると 必ず矛盾が生じ，フラストレーションを抱え込ん でいる。その結果，多くのスピン配置のエネルギ 一準位が縮退し，長距離スピン秩序の発生が抑制 される。私達の日常生活でも，2つ（以上）の選 択肢の中で葛藤することがあるが，ここで起きて いるのはまさに同じことである.

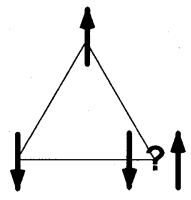

Fig.1 Geometrical spin frustration in triangle lattice.

フラストレーション系の研究の歴史は古く, 1973 年に P. W. Anderson は 2 次元三角格子におけ る基底状態に関する有名な論文を発表している [1]．計算によれば，スピンが結晶のように格子 を組む状態（spin solid）よりも，スピンがペアの 相手を変えながら液体のように相関を持って動く 状態（spin liquid）の方がエネルギーが低い。この ような新規な基底状態, 磁性の期待が幾何学的ス ピンフラストレーション系の研究の大きな動機の 一つとなっている.

\section{2. 幾何学的スピンフラストレーションの代表例}

幾何学的スピンフラストレーションが強く現れ る例として 2 次元的な格子では, 三角格子 (Fig.2(a)), kagomé 格子[2] (Fig.2(b))，3 次元的 な格子では fcc 格子 (Fig.2(c)), パイロクロア格子 [3], スピネル格子[4]などがある. 三角格子, fcc 格子は隣り合う三角格子が辺を共有する

(Edge-sharing) のに対し, kagomé 格子，パイロ クロア格子，スピネル格子は隣り合う三角格子が 頂点を共有(corner-sharing)している (Fig.2). Edgesharing 型の場合，お互いのスピンが互いに 120 度 をなすようなスピン配置がユニークに決まりうる のに対し, Corner-sharing 型の場合 120 度回転す る方向が 2 つあるた縮退が残り，Edge-sharing 型よりもフラストレーションを起こす傾向が強い. 3 次元的な格子では，三角格子の組み合わさった 正四面体がユニットとなる. 本稿で取り上げる fcc 格子は正四面体が Edge-sharing 型で組み合わさっ た構造を持つ. 幾何学的スピンフラストレーショ ンを起こす 3 次元的な格子の中では，一番シンプ ルな構造をしており, 理論と実験の比較が比較的 容易な系である。また 3 次元的であるため，量子 スピン摇らぎが小さく, 幾何学的フラストレーシ ヨンによるスピン摇らぎのみを研究するのに適し ている。このような幾何学的フラストレーション による動的なスピン摇らぎを調べるには，スピン 相関のエネルギー，Q依存性を調べられる中性子 散乱実験が必要不可欠であり，ここでは fcc 格子 を持つ反強磁性体 $\mathrm{NiS}_{2}$ について行った中性子散 乱実験，物性測定について報告する。 
(a)

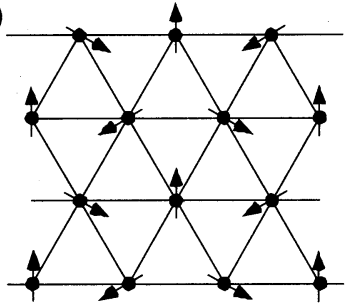

(b)

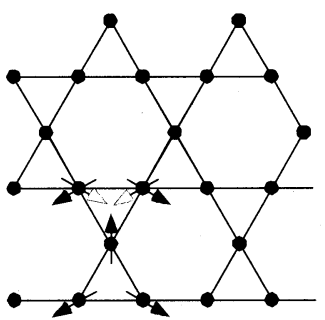

(c)

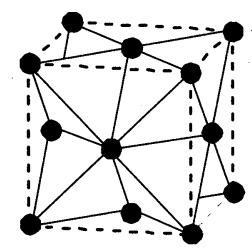

Fig.2 Examples of frustrated systems (a) triangle lattice (b) kagomé lattice (c) fcc lattice. Arrows show spins.

\section{3. $\mathrm{NiS}_{2}$ の磁性}

$\mathrm{NiS}_{2}$ において $\mathrm{Ni}$ は+2 価となり $3 \mathrm{~d}$ 電子を 8 個持 ち, low spin stateをとり $\mathrm{S}=1$ となる. バンド描像 では金属だが，強い電子相関により $3 \mathrm{~d}$ の $\mathrm{e}_{\mathrm{g}}$ バン ドが分裂し，モット絶縁体（電荷移動型）となっ ている[5].

$\mathrm{NiS}_{2}$ の磁性は非常にユニークである．温度を下 げていくと $\mathrm{T}_{\mathrm{N} 1}=40 \mathrm{~K}$ で type $\mathrm{I}$ 反強磁性

$\left(\mathbf{Q}_{\mathrm{AF}}=(1,0,0)\right)$ が出現し， $\mathrm{T}_{\mathrm{N} 2}=30 \mathrm{~K}$ で type II 反強 磁性（ $\left.\mathbf{Q}_{\mathrm{AF}}=(1 / 2,1 / 2,1 / 2)\right)$ が 1 次転移的に加わる

(Fig.3). 加えて, type II 反強磁性とともに弱強磁 性が出現し，30K 以下でこれら 3 つの秩序が共存 している[6].

また， $\mathrm{T}_{\mathrm{N} 1}$ よりかなり高温から短距離磁気相関 による異常が現れる. Fig.4 は $\mathrm{NiS}_{2}$ の逆一様磁化 率の温度変化である [7]. 図中の実線は $T=500 \mathrm{~K}$ 以 上の領域におけるキュリーワイス則へのフィッテ イングである。キュリーワイス温度 $\left(\Theta_{\mathrm{CW}}\right)$ と $\mathrm{T}_{\mathrm{N}}$ の比はスピンフラストレーションの強さを示す目 安となるが, $\mathrm{NiS}_{2}$ の值, $\Theta_{\mathrm{CW}}(=1250 \mathrm{~K}) / \mathrm{T}_{\mathrm{Nl}} \sim 30$ は 他のフラストレート系 $\left(\mathrm{LiCrO}_{2}\right.$ 三角格子 : 16, $\mathrm{ZnCr}_{2} \mathrm{O}_{4}$ スピネル : 24）と比べても大きな值とな っている. 逆一様磁化率は $350 \mathrm{~K}$ 付近からキュリ 一ワイス則からずれ始め, $\mathrm{T}_{\mathrm{N} 1}$ の 9 倍もの高温か らの短距離磁気相関の発達を示唆している.

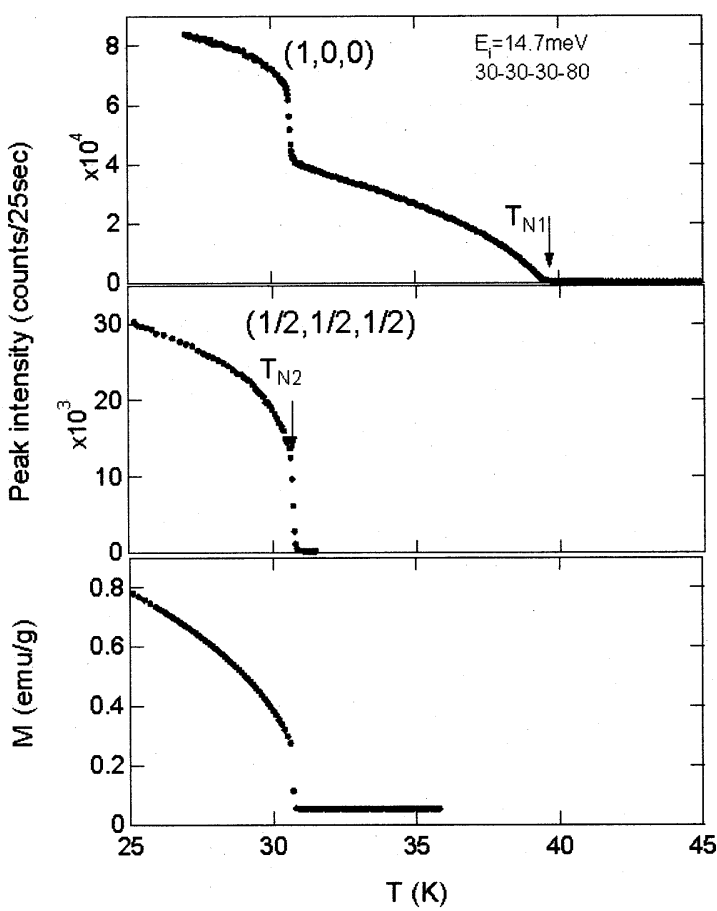

Fig.3 Temeprature dependences of the type I $\quad\left(\mathbf{Q}_{\mathrm{AF}}=(1,0,0)\right)$ and II $\quad\left(\mathbf{Q}_{\mathrm{AF}}=(1 / 2,1 / 2,1 / 2)\right)$ antiferromagnetic Bragg reflection, and magnetization.

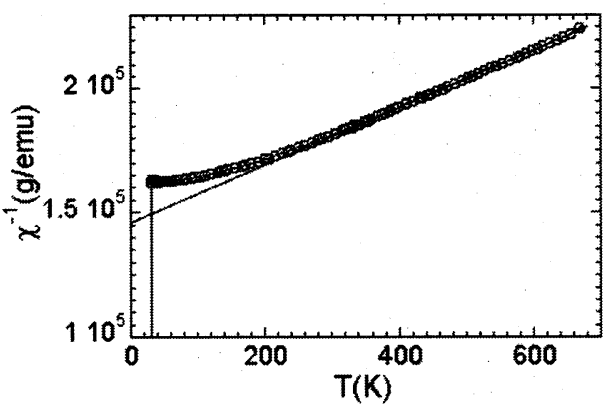

Fig.4 The temperature dependence of inverse magnetic susceptibility.

\section{4. 中性子散乱実験}

幾何学的スピンフラストレーションによる反強 磁性スピン摇らぎの $\mathbf{Q}$ 依存性を調べるため, 中性 子非弾性散乱実験を原研改 3 号炉の中性子 3 軸分 光器 TOPAN で行った. 励起エネルギーは $2 \mathrm{meV}$ に固定し， mesh スキャンを type I AFのみが存在 する $\mathrm{T}=32 \mathrm{~K}$ と type I, type II AF が共存する $\mathrm{T}=11 \mathrm{~K}$ で測定した (Fig.5). 散乱面は type I AF $\left(\mathbf{Q}_{\mathrm{AF}}=(100)\right)$, type II AF $\left(\mathbf{Q}_{\mathrm{AF}}=(1 / 2,1 / 2,1 / 2)\right)$ を両方観測できる $(h k k)$ 面を用いた。逆格子空間において fcc 結晶格 子の Brillouin zone境界は図のような正六角形と正 方形の面からなる多面体をなし, type IAF の磁気 Bragg 点 $(\bigcirc)$, type II AF の磁気 Bragg 点 $(\triangle)$ は それぞれ正六角形と正方形の面の中心に位置する (Fig.5(a))。(hkk)散乱面では Fig.5(b)の様に fcc 結 晶格子の Brillouin zone 境界 (点線) は蜂の单 (honeycomb) パターンを示す. Fig.5(c),(d)の等高 
(a)

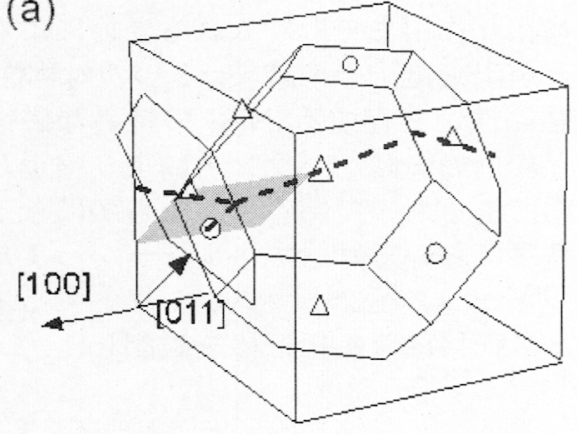

(b)

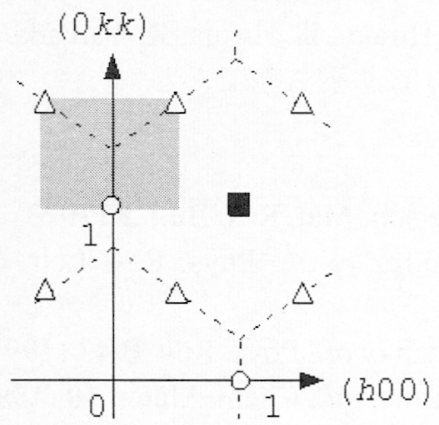

(c)

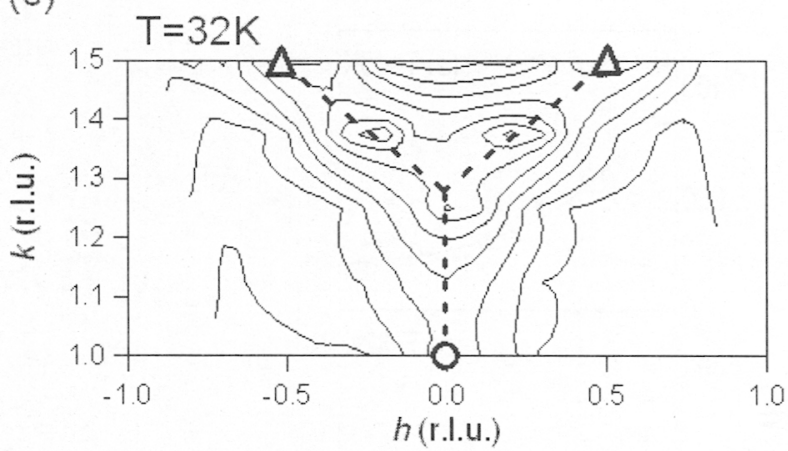

(d)

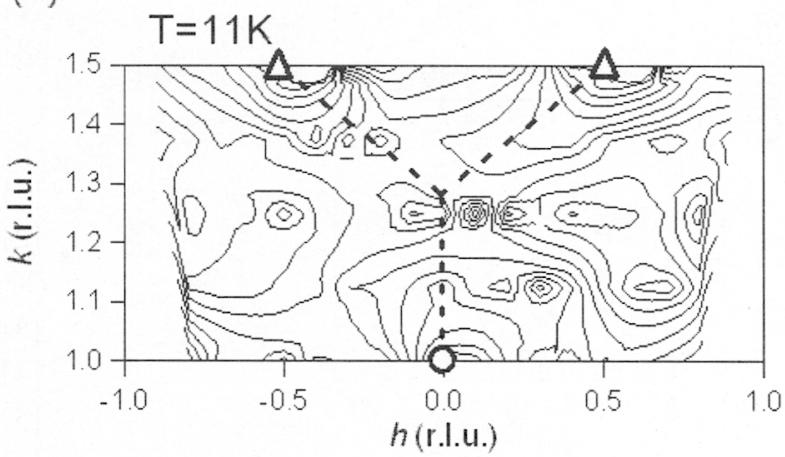

Fig. 5 Contour plots of scattering intensities at $\omega=2 \mathrm{meV}$. Scanned region is shown by gray in (a)reciprocal space (b) ( $h k k$ ) scattering plane. Open circles and triangles denote type I and II AF Bragg points, respectively. Dotted lines show Brillouin zone boundary of fce lattice.

線プロットは, Fig.5(a),(b)においてグレーで示し た領域の散乱強度を示している。 $\mathrm{T}=32 \mathrm{~K}$ において

(Fig.5(c)）散乱強度は fcc 結晶格子の Brillouin zone 境界に沿って現れた。このような Brillouin zone 境界線上に現れる磁気散漫散乱は他の幾何学 的スピンフラストレーションのある系でも観測さ れており，フラストレート系に共通した特徴であ る[8]. Type II AF order が出現し, 縮退が完全に解 けた $\mathrm{T}=11 \mathrm{~K}$ において, この特徴的な磁気散漫散乱 シグナルは消失し, 代わりに磁気 Bragg 点 $(O$, \）のまわりにスピン波励起が現れる (Fig.5d). この磁気散漫散乱の $\mathbf{Q}$ 分布を説明するために, 常磁性状態における $\chi(\mathbf{Q})$ を以下の式よりシミュレ ートした[7].

$$
\chi(\mathbf{Q}) \sim\left\{\delta+\left[1-\mathrm{J}(\mathbf{Q}) / \mathrm{J}\left(\mathbf{Q}_{\mathrm{AF}}\right)\right]\right\}^{-1}
$$

ここで $は$ 現在の温度とネール温度との差を表す 量で，J(Q)は第 3 近接交換相互作用まで考慮した 交換相互作用のフーリエ変換である。 $\mathrm{J}\left(\mathbf{Q}_{\mathrm{AF}}\right)$ は市 一ル温度において $\chi(\mathbf{Q})$ が発散する波数べクトルで, 最近接 $\left(\mathrm{J}_{1}\right)$, 第 2 近接 $\left(\mathrm{J}_{2}\right)$, 第 3 近接 $\left(\mathrm{J}_{3}\right)$ 交換相 互作用の比により, $\mathrm{Q}_{\mathrm{AF}}=(1,0,0)$ :type I, $(1 / 2,1 / 2,1 / 2)$ : type II, $(1,1 / 2,0)$ :type III などの值を取る. Fig.6 にシ ミュレーションの結果を示す。このシミュレーシ ヨンは、2 $15 \mathrm{meV}$ の強度のエネルギー積分值につ いて実験值との比較を行っている。 $\mathrm{NiS}_{2}$ で観測さ れた 磁気散漫散乱の $\mathbf{Q}$ 分布を最もよく再現する のは, $\mathrm{J}_{2} / \mathrm{J}_{1}=0.43, \mathrm{~J}_{3} / \mathrm{J}_{1}=0.16$ の組み合わせであった。 この組み合わせは type I 相が安定化する領域と

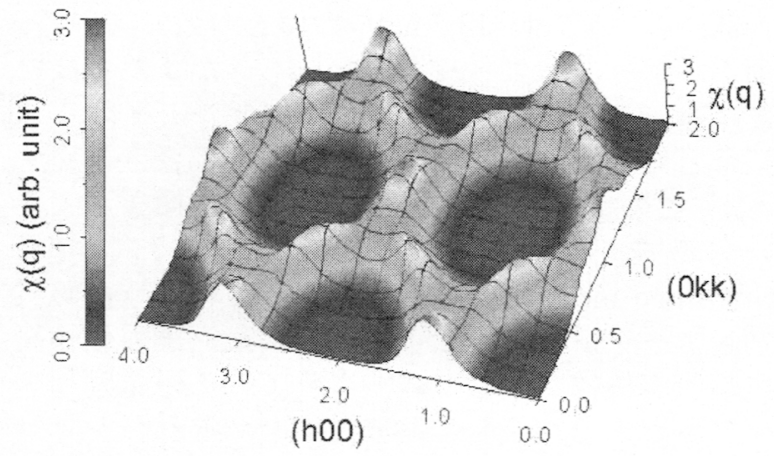

Fig.6 Simulation of $\chi(\mathrm{Q})$ in $\mathrm{NiS}_{2}$.

type II 相が安定となる領域の境界に非常に近い事 から， $\mathrm{NiS}_{2}$ において type I AF と type II AF がエネ ルギー的にほぼ縮退していることを示している。 また，シミュレーションにおいて $\mathrm{J}_{2} / \mathrm{J}_{1}, \mathrm{~J}_{3} / \mathrm{J}_{1}$ の組 み合わせの広い領域で, Brillouin zone 境界線上に ピークが現れた。この事から, Brillouin zone 境界 線上に現れる磁気散乱は幾何学的スピンフラスト レーション系に generic な特徵であると考えられ る.

Fig.7 に磁気散漫散乱のエネルギー依存性を示 す. 常磁性状態 $\left(T>T_{\mathrm{N} 1}=40 \mathrm{~K}\right)$ においては Lorentzian でよく表される散漫散乱である。温度を下げてい くと Type I AF の出現している32K においてスペ クトラムは高エネルギーにシフトする。縮退が解 けフラストレーションが解消されている17Kにお いて磁気散漫散乱は消失し, 代わりに $13 \mathrm{meV}$ の強 


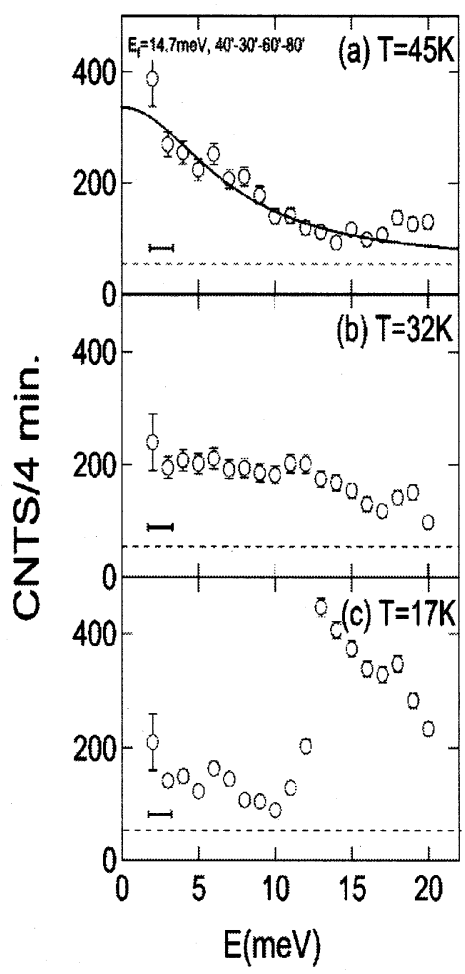

Fig. 7 Constant-Q profiles at the type I AF Bragg (100).

度が増大している。このエネルギーは磁化率のキ ユリーワイス則から求めた交換相互作用 $J=3 \mathrm{k}_{\mathrm{B}} \Theta_{\mathrm{CW}} / \mathrm{z} S(S+1)=13.5 \mathrm{meV}$ の值と一致している. 縮退が解け，低エネルギーの摇らぎが J だけ高い エネルギーにシフトする点は, スピンパイエルス 転移と似ており興味深い[9]. 紙面の都合上割愛す るが, この $13 \mathrm{meV}$ 以上の励起は非常に傾きが大き い分散を示す。 また $13 \mathrm{meV}$ 以下においても Goldstone mode が存在している. このような磁気 励起スペクトラムの 2 重構造は, 最近銅酸化物高 温超伝導体に共通して観測されている磁気励起ス ペクトラムと類似しており $[10,11]$ ，それらをフラ ストレートした反強磁性相関という視点から捉え ることが出来るかもしれない.

\section{5. まとめ}

中性子散乱により $\mathrm{NiS}_{2}$ の常磁性相において fcc 格子の Brillouin zone 境界に沿う磁気散漫散乱の存 在を明らかにした。この磁気散漫散乱の $\mathbf{Q}$ 分布を，
第 3 近接交換相互作用まで取り入れることにより 再現することが出来た。その結果，2つの対称性 の異なる反強磁性が共存する $\mathrm{NiS}_{2}$ の特異な磁性 は，交換相互作用の微妙なバランスにより縮退し たスピン状態によるものである事が明らかになっ た，長距離秩序においては低エネルギーから J だ け高いエネルギーへスペクトラムがシフトするス ピンパイエルス転移に似た相転移を観測した。

謝辞

本研究は A. S. Mishchenko, I. V. Solovyev, N. Nagaosa, H. Hiraka, K. Hirota, K. Yamada, Y. Endoh 各氏との協力によるものである.

参考文献

[1] P. W. Anderson, Mat. Res. Bull. 8 (1973) 153.

[2] A. P. Ramirez et al., Phys. Rev. Lett. 64 (1990) 2070.

[3] J. E. Greedan et al., Phys. Rev. B 43 (1991) 5682.

[4] J. E. Greedan et al., Chem. Mater. 10 (1998) 3058.

[5] A. Fujimori et al., Phys. Rev. B 54 (1996) 16329.

[6] T. Miyadai et al., J. Phys. Soc. Jpn. 38 (1975) 115.

[7] M. Matsuura et al., Phys. Rev. B 68 (2003) 94409.

[8] S.-H. Lee et al., Phys. Rev. Lett. 84 (2000) 3718.

[9] O. Fujita et al., Phys. Rev. Lett. 74 (1995) 1677.

[10] J.M. Tranquada et al. Nature 429 (2004) 534.

[11] S.M.Hayden et al. Nature 429 (2004) 531. 